\title{
EL PERJUICIO ECONÓMICO COMO ELEMENTO DE CONFIGURACIÓN DE LA GRAVEDAD DEL DESPIDO
}

\author{
EnRiQue Munita Luco*
}

\begin{abstract}
RESUMEN: El artículo corresponde a un estudio de la jurisprudencia sobre la causal de terminación del contrato de trabajo del artículo $160 \mathrm{~N}^{\circ} 7$ del Código del Trabajo, "incumplimiento grave de las obligaciones que impone el contrato". Específicamente nos referimos al entendimiento del perjuicio económico como requisito de la configuración de la gravedad del incumplimiento. La determinación de la gravedad corresponde a un razonamiento valorativo que ha generado jurisprudencia opuesta en circunstancias de hecho muy similares. Nos abocamos a los diferentes aspectos que se han tenido en cuenta al efectuar dicho razonamiento y las circunstancias que motivarían los diferentes criterios observados. Finalmente, señalamos conclusiones y una propuesta para reducir dicha disparidad de criterios.
\end{abstract}

Palabras clave: despido, incumplimiento, grave, obligaciones, contrato, perjuicio económico.

\begin{abstract}
The article consists in the study of the jurisprudence regarding the termination of employment contract on the grounds of a serious non-compliance of the contractual obligations undertaken by the employee (article $160 \mathrm{~N}^{\circ} 7$ Labor Code). Specifically, we refer to the understanding of the monetary damages as a requisite for the configuration of the seriousness of the breach of the obligations by the employee. The determination of the seriousness corresponds to a reasoning that has originated contradictory jurisprudence in similar circumstances. We review the different aspects that have been considered in that reasoning and the circumstances that have caused the different criteria. Finally, we include the conclusions of the study and a proposal to reduce the differences seen in the jurisprudence.
\end{abstract}

Key words: dismissal, serious non-compliance, breach, obligations, contract, monetary damages.

\section{INTRODUCCIÓN}

El artículo 160 número 7 del Código del Trabajo (en adelante CdT) establece como causal de término del contrato de trabajo el que el trabajador incurra en un "incumplimiento grave de las obligaciones que impone el contrato". Como es consecuencia de la aplicación de esta causal que el trabajador quede privado del derecho a las indemnizaciones por término de contrato, la gravedad del incumplimiento ha sido materia de constante discusión judicial y, por lo tanto, de abundante jurisprudencia. En el presente trabajo nos abocaremos al estudio del perjuicio económico como requisito para la configuración de tal gravedad. El tema resulta interesante pues es posible observar que, aun en presencia de hechos similares, la jurisprudencia no exhibe uniformidad de criterios: existen casos en que al perjuicio se le asigna una mayor importancia para la determinación de la gravedad y otros en los que prácticamente no se le considera.

La determinación de la gravedad consiste en un razonamiento valorativo en el que se analiza la conducta del trabajador de acuerdo a las circunstancias del caso. Se deben tener en cuenta diversos aspectos, entre otros, el perjuicio económico que pudiere haber ocasionado. Veremos

\footnotetext{
* Abogado. Licenciado en Ciencias Jurídicas y Sociales, Universidad de Concepción. Magister en Investigación Jurídica, Universidad de Los Andes. Profesor de Diplomado Derecho de La Empresa, Universidad de Los Andes.
} 
que la relevancia de este elemento depende de distintos factores: en especial si el incumplimiento contractual implica una infracción a la fidelidad y lealtad debidas al empleador.

Comenzaremos con una visión general de la extinción del contrato por incumplimiento grave de las obligaciones que impone el contrato, para enseguida detenernos en la gravedad del incumplimiento y en particular en la relevancia del perjuicio económico para la calificación de la misma. Desde una perspectiva jurisprudencial contrastaremos aquellos casos en los que a este elemento ha sido considerado como un requisito para la configuración de la gravedad con aquellos en que no. En este último punto nos referiremos a las situaciones de infracción a la buena fe contractual, de daño potencial y aquellas en que el daño se ha provocado a un compañero de labores. Posteriormente veremos casos en que pese a existir un daño patrimonial a la empresa no se considera que exista incumplimiento grave. Finalizaremos con una reflexión acerca de los factores que determinarían la importancia que se asigna al perjuicio para la calificación de la gravedad.

\section{EL DESPIDO POR INCUMPLIMIENTO GRAVE DE LAS OBLIGACIONES CONTRACTUALES}

\subsection{Aspectos generales}

El artículo 160 CdT contempla diversas causales que permiten al empleador poner término al contrato de trabajo sin que proceda el pago de indemnización alguna como consecuencia de dicho cese ${ }^{1}$. Todas ellas constituyen formas graves de violación de los deberes derivados del contrato de trabajo ${ }^{2}$.

Dentro de éstas, la del número 7, que corresponde al "incumplimiento grave de las obligaciones que impone el contrato", es la más genérica por cuanto en ella es posible encuadrar diversas conductas reprochables en las que puede incurrir el trabajador ${ }^{4}{ }_{-}^{5}$; requiere de la concurrencia de dos requisitos copulativos: el incumplimiento de una obligación contractual y que éste sea grave ${ }^{6}$.

La jurisprudencia se ha referido generalmente a éstas como causales de caducidad del contrato: CA Concepción 13-11-2007, rol 264-2007; CA Santiago 15-05-2007, rol 4034-2006; CA Concepción 21-11-2007, rol 380-2007; CA Iquique 3-9-2007, rol 692007; CA Concepción 23-08-2007, rol 4258-2006 y CA Punta Arenas 13-08-2007, rol 18-2007. Dicha expresión no se condice con el concepto de caducidad en su sentido jurídico más preciso, que corresponde a aquella figura que determina de modo automático la extinción de ciertos derechos, poderes o facultades, si no se realiza un acto específico dentro del plazo fijado por la ley DomínGuez Águila, Ramón. La Prescripción Extintiva. Doctrina y Jurisprudencia. Santiago, Chile: Editorial Jurídica de Chile, 2004 , p. 127.

2 Irureta Uriarte, Pedro P. "La Falta de Probidad como causa de extinción del contrato de trabajo", en: VVAA. Estudios en Homenaje al profesor William Thayer. Santiago, Chile: Sociedad Chilena de Derecho del Trabajo y de la Seguridad Social, Santiago, 1998, p. 116.

3 CA Rancagua 6-6-2008, rol 65-2008.

4 CA Valdivia 27-8-2002, rol 1629-2002, CS 20-1-2003, rol 3810-2002.

5 Thayer Arteaga, William; Novoa Fuenzalida, Patricio. Manual de Derecho del Trabajo. Tomo III. Santiago, Chile: Editorial Jurídica de Chile, 1998, p. 59.

6 CS 13-8-2002, rol 1734-2002; CS 29-12-2005, rol 2864-2004, CA Talca 25-8-2005, rol 2258-2004; CS 8-6-2006, rol 61192005 y CA Arica 26-11-2007, rol 115-2007.

7 En este mismo sentido en el derecho espańol, tampoco basta cualquier incumplimiento para ser causa de despido: debe ser uno cualificado. Seńala el Estatuto de los Trabajadores, en adelante "ET", que el incumplimiento del trabajador debe ser "contractual, grave y culpable". Dicho cuerpo normativo contiene una fórmula general definitoria o descriptiva del incumplimiento resolutorio, como asimismo, "una lista de causas de despido que la explaya" Alonso Olea, Manuel; Casas BaAmonde, María Emilia. Derecho del Trabajo-24a edición-. Madrid, Espańa: Civitas, 2006, p. 510. Dentro de ellas el despido disciplinario fundado en "la transgresión de la buena fe contractual, así como el abuso de confianza en el desempeńo del trabajo” del artículo 54.2.d) ET, es una causa que 
Sobre la naturaleza de esta causal más bien podría entenderse que estamos frente a una verdadera condición resolutoria del contrato ${ }^{8}$, pues el negocio jurídico impone obligaciones al trabajador, cuyo incumplimiento grave confiere derecho al empleador a poner justificadamente término a la relación laboral ${ }^{9}{ }^{10}$, es decir, se trata de una resolución unilateral, que tiene lugar por decisión del empleador y fundada en un incumplimiento previo del trabajador ${ }^{11}$. Se afirma así que, en cierta manera, el empleador es juez y parte a la vez, puesto que puede hacer expirar el contrato, inmediata y directamente, frente al incumplimiento del trabajador ${ }^{12}$. De esta manera, no corresponde a aquella resolución prevista en nuestro derecho común para resolver obligaciones recíprocas en caso de incumplimiento de uno de los obligado ${ }^{13}$ ya que es un mecanismo mucho más expedito, porque deja en manos del empleador la facultad de romper la relación laboral sin necesidad de acudir al juez ${ }^{14}$.

Asimismo la sanción de esta causal se considera la más grave impuesta por la comisión de una falta laboral ${ }^{15}$, pues conlleva la disolución de la relación laboral ${ }^{16} \mathrm{y}$ la pérdida de las indemnizaciones por término de contrato ${ }^{17}$. Con todo, una vez aplicada la causal por parte del empleador, si el trabajador la impugna ante el tribunal del trabajo, el juez deberá valorar la conducta para resolver si corresponde a una infracción que amerite extinguir el contrato de trabajo sin derecho a indemnización alguna ${ }^{18}$.

Como obligaciones contractuales no sólo se deben considerar aquellas explícita y formalmente asumidas por el trabajador en el texto del contrato de trabajo, sino que también las que con ocasión de los servicios impone la ley, la voluntad de las partes y la propia naturaleza del vínculo ${ }^{19}$.

puede comprender muy diversos comportamientos. En todo caso, cabe reiterar que el ET en su artículo 54.2 manifiesta la opción de no establecer una remisión genérica a cualesquiera incumplimientos graves, sino que, como dijimos antes, ha preferido el sistema de una lista de causas Montoya Melgar, Alfredo. Derecho del Trabajo. Madrid, España: Tecnos, 1999, p. 465.

8 Entendemos la resolución de un contrato como la "extinción de este contrato a causa de la inejecución de sus obligaciones por parte de uno de los contratantes”. Cfr. Larroumet, Christian. Teoría general del contrato. Vol. II. Bogotá, Colombia: Editorial Temis S.A., 1993, pp. 143-144.

9 Thayer Arteaga, William; Novoa Fuenzalida, Patricio, op. cit. (n. 5), p. 59. La jurisprudencia, aunque de manera más bien aislada, también lo ha entendido de la misma manera.

10 CA San Miguel 15-7-2005, rol 318-2004; CS 22-5-2006, rol 4336-2005.

11 Alonso Olea, Manuel; Casas Baamonde, María Emilia. Derecho del Trabajo -24a edición-. Madrid, España: Civitas, 2006, p. 510 .

12 Macchiavello, Guido. Derecho del Trabajo. Tomo I. Santiago, Chile: Fondo de Cultura Económica, Santiago, 1986 , p. 517.

13 Según la doctrina civilista tradicional "si la condición resolutoria se sobreentiende siempre en un contrato sinalagmático, es justamente porque cada contratante, aún cuando no haya cláusula resolutoria expresa, puede pedir al juez que decrete la resolución en el caso que el otro contratante no cumpla su obligación" Larroumet, Christian, op. cit. (n. 7), p. 147. En el derecho civil comparado el remedio generalmente aceptado es que el acreedor tiene derecho a declarar unilateralmente la resolución por incumplimiento del deudor Barros Bourie, Enrique. "Finalidad y alcance de las acciones y los remedios contractuales", en Guzmán Brito, Alejandro (edit.). Estudios de Derecho Civil III, Jornadas Nacionales de Derecho Civil, Valparaíso, 2007. Santiago, Chile: Legal Publishing, 2008, p. 423.

14 Martín Valverde, Antonio. Rodríguez-Sañudo Gutiérrez, Fermín; García Murcia, Joaquín. Derecho del Trabajo. Décimo Quinta Edición. España, Madrid: Tecnos, 2006, p. 703.

15 Alonso Olea, Manuel; Casas Baamonde, María Emilia, op. cit. (n. 11), p. 510.

16 Montoya Melgar, Alfredo, op. cit. (n. 7), p. 464.

17 CS 8-10-2008, rol 5078-2008.

18 CA Santiago, 27-12-2007, rol 1.543-2007, CS 17-03-2008, rol 802-2008.

19 CS 13-8-2002, rol 1734-2002 y CA La Serena 4-2-2009, rol 193-2008. 


\subsection{LA GRAVEDAD DEL INCUMPLIMIENTO}

Como apuntábamos uno de los aspectos determinantes para configurar esta causal es que estemos ante un incumplimiento grave ${ }^{20}$. Se ha considerado que debe consistir en un acto que "afecte en su esencia el acatamiento de las obligaciones contractuales" ${ }^{21}$ y que sea de tal magnitud que determine necesariamente el quiebre de la relación laboral e impida la convivencia normal entre uno y otro contratante ${ }^{22}$; o bien, tratarse de conductas del trabajador que lesionen y/o amenacen en cierto modo la estabilidad de la empresa ${ }^{23}$. En otras palabras, la conducta del trabajador debe ser un impedimento para que continúe en la empresa ${ }^{24}{ }^{25}$, puesto que pone en peligro el equilibrio de intereses jurídicos establecidos a través del contrato de trabajo ${ }^{26}$.

La gravedad puede referirse tanto al incumplimiento del deber principal del trabajador, esto es la obligación de ejecutar el trabajo o servicio para el que fue contratado, como a deberes accesorios del mismo. Estos últimos pueden corresponder tanto a obligaciones de hacer: tales como respetar las normas de seguridad (usar casco en una obra de construcción); como también, en forma mayoritaria, a obligaciones de no hacer generalmente referidas a la buena fe contractual: como la no comisión de delitos en ejercicio de sus funciones (apropiación indebida u otros), no recibir sobornos, no quebrantar su deber de confidencialidad, no competir con su empleador, no

20 El problema de la gravedad del incumplimiento está también presente en el derecho común. Específicamente, se le ha estudiado al revisar la resolución del contrato por el incumplimiento de una de las partes. Se ha seńalado que para que proceda la resolución de un contrato debe tratarse de un incumplimiento grave y que no basta cualquier incumplimiento de obligaciones accesorias o complementarias. Ello sin perjuicio que en ocasiones la inejecución de una de ellas podría determinar el incumplimiento de la propia obligación principal, con lo cual existiría razón suficiente para la resolución. Se ha dicho que cuando estamos frente a un "incumplimiento simplemente parcial o de cumplimiento defectuoso, la inejecución de una mínima parte de la prestación o un defecto de escasa enjundia y fácilmente subsanable, no deben dar lugar a la resolución del contrato, porque el ejercicio de la facultad resolutoria se presenta en tales supuestos como contrario a los dictados de la buena fe y constitutivo de lo que puede llamarse abuso en el ejercicio de aquella facultad”. Diez-Picazo, Luis. Fundamentos del Derecho Civil Patrimonial-5a Edición-. Vol. II España, Madrid: Civitas, 1996., p. 710.

Messineo sostiene que la buena fe contractual conlleva el rechazo de la resolución como sanción en el caso de incumplirse una obligación de escasa importancia, agregando que la misma debe ser la conclusión en caso de infracción a la prestación principal si el incumplimiento es de escasa entidad Messineo, Francesco. Doctrina general del contrato. Tomo II. Buenos Aires, Argentina: Ediciones Jurídicas Europa-América, 1979, p. 348. La jurisprudencia de nuestros tribunales superiores, desde hace ya largo tiempo, ha dado acogida a este criterio. Lo mismo puede decirse de nuestra doctrina civilista más tradicional. En cada caso debe examinarse si la acción resolutoria se ha ejercido dentro de los dictados de la buena fe AlCalde Rodríguez, Enrique. "Acción resolutoria y excepción de contrato no cumplido", en: Actualidad Jurídica, año IV, No 8, Santiago, Chile, julio 2003, pp. 79-80. "El requisito de esencialidad impide que la resolución devenga en un pretexto para deshacerse de contratos inconvenientes" Barros Bourie, Enrique, op. cit. (n. 13), pp. 422-423.

21 JLT Concepción, 27-01-2003, rol 3128, CA Concepción 21-7-2003, rol 962-2003, CS 27-07-2004, rol 3568-2003.

22 CS 13-08-2002, rol 1734-2002, CS de 28-08-2002 rol 2468-2002 y CS 13-06-2013 rol 1242-2013.

23 CS 8-10-2008, rol 5078-2008 y CS 13-06-2013 rol 1242-2013.

24 Petit, François. El despido disciplinario en Francia, en: Gil y Gil, José Luis; Del Valle, José Manuel (Coords.). El despido disciplinario, Homenaje al Profesor Juan Antonio Sagardoy B. Madrid, Espańa: Ediciones Cinca, 2009, p. 611.

25 En este sentido la Corte de Casación francesa ha dicho que "La faute grave est celle qui, par son importance, rend impossible le maintien du salarié dans l'entreprise ..." (Soc. 2 fébrier 2005, Bull.2005, V. n 42). "C'est bien l'importance de la faute du salarié qui doit rendre imposible, pour le employeur, de tolérer même pendant une durée limitée, la présence physique du salarié dans léntreprise (Soc. 27 septembre 2007, Bull, 2007, V, nº 146).

26 Gorelli Hernández, Juan. "Deber de obediencia y despido por desobediencia”, en: Revista Española de Derecho del Trabajo N 87/1998. Jurisprudencia. España, Madrid. También en Domblas María Asunción; Fernández Baraibar, Maite. Causas del Despido Disciplinario. Vol. II. Pamplona, España: Thomson Aranzadi, 2007, p. 119. 
incurrir en comportamientos de acoso laboral o de discriminación respecto de sus compañeros de labores, etc. ${ }^{27}$.

Ante la acción intentada por el trabajador para impugnar la justificación de la causal, el juez determinará si los hechos en que se funda están dotados de la gravedad suficiente para justificar la aplicación de la misma. El juez examina, sobre la base de la entidad del incumplimiento, si el interés del empresario de cesar el contrato, sin pagar indemnizaciones, debe prevalecer sobre el interés del trabajador. La justificación del despido depende así de cómo los jueces del trabajo aprecien los intereses del trabajador y del empresario ${ }^{28}$.

\subsection{Determinación de la GRAVEDAd}

La determinación de la gravedad del incumplimiento corresponde a un problema de valoración que supone ponderar los hechos y sus efectos para determinar si ésta concurre ${ }^{29}$. Esta valoración debe considerar todos los aspectos, objetivos y subjetivos de la situación, teniendo presente sus antecedentes, las circunstancias concurrentes, y la realidad social ${ }^{30}$. Y es que la gravedad es un elemento susceptible de valoración, en orden a utilizar elementos que acentúan (agravantes) o disminuyen (atenuantes) la entidad de la conducta del trabajador ${ }^{31}$, para evitar así una actitud sancionadora absolutamente automática.

De este modo se debe efectuar un análisis individualizado de dicha conducta, que permita lograr una proporcionalidad entre el incumplimiento del trabajador y la sanción que recibe ${ }^{32}$. Es decir, es necesario atender al incumplimiento mismo y las circunstancias en que éste se produzca, el ámbito o medio de trabajo en que tenga lugar, el puesto de trabajo que se ocupe y la cualificación, profesión u oficio que se tenga, etc. ${ }^{33}$. Por consiguiente se trata de una cuestión eminentemente casuística ${ }^{34}$. La falta del trabajador puede corresponder a un hecho aislado o a uno que se repite o reitera en el tiempo. Colabora a configurar la gravedad la continuidad, habitualidad y repetición de la conducta ${ }^{35} 36$ ya que, como es sabido, la reiteración es un agravante en todo derecho sancionatorio $^{37}{ }^{38}$. Sin embargo, es perfectamente posible que la infracción consista en un hecho

27 SeIfERT, Achim. El despido basado en la conducta del trabajador en el derecho alemán, en: en: Gil y GiL, José Luis; DeL VALLE, José Manuel (Coords.). El despido disciplinario, Homenaje al Profesor Juan Antonio Sagardoy B. Madrid, España: Ediciones Cinca, 2009, p. 588.

$28 \quad$ Ibid, p. 587.

29 CA Santiago 27-12-2007, rol 1543-2007.

30 Albiol Montecinos, Ignacio; Camps Ruiz, Luis Miguel; López Gandía, Juan; Sala Franco, Tomás. Derecho del Trabajo. Tomo II. Valencia, Espańa: Tirant Lo Blanch; 2003, p. 575.

31 Gorelli Hernández, Juan, op. cit. (n. 26), p. 126.

32 Ibid., pp. 126 y 127.

33 Alonso Olea, Manuel; Casas Baamonde, María Emilia, op. cit. (n. 11), p. 516.

34 Sierra Herrero, Alfredo. "Extinción del contrato de trabajo por voluntad del trabajador (jurisprudencia en unificación de la doctrina sobre el artículo 50 ET)”, en: Actualidad Laboral N 6, marzo 2007, Madrid, Espańa, La Ley.

35 Albiol Montecinos, Ignacio; Camps Ruiz, Luis Miguel; López Gandía, Juan; Sala Franco, Tomás, op. cit. (n. 30 ), p. 575.

36 Estos elementos han sido recogidos por la jurisprudencia: CS 11-10-2007, rol 599-2007 y CA Antofagasta 30-4-2009, rol 402009

37 Alonso Olea, Manuel; Casas Baamonde, María Emilia, op. cit. (n. 11), p. 516.

38 "Desde antiguo la reincidencia ha obrado como circunstancia agravante de la responsabilidad criminal" Labatut GLENA, Gustavo. Derecho Penal. Tomo I. Santiago, Chile: Editorial Jurídica de Chile, 1995, p. 229. 
aislado, con tal que éste tenga la entidad suficiente para ser considerado grave, puesto que la repetición de la conducta no es el único elemento para determinar la gravedad ${ }^{39}$.

Ciertamente, una de las circunstancias relevantes que la jurisprudencia suele considerar para calificar la gravedad de una infracción laboral consiste en la existencia o ausencia de perjuicios producidos como consecuencia de la misma. Se trata de una materia compleja pues dicho análisis no se agota en constatar si se ha originado o no un daño para la empresa -o terceros-, sino que muchas veces sobre la base de daños o perjuicios debidamente comprobados, los jueces del trabajo proceden a una valoración respecto de si ellos presentan la suficiente entidad que amerite calificar el incumplimiento del trabajador como "grave", con todas las consecuencias que ello significa.

\section{EL PERJUICIO ECONÓMICO COMO ELEMENTO DE CONFIGURACIÓN DE LA GRAVEDAD}

\subsection{Aspectos Generales}

El incumplimiento contractual del trabajador podría ocasionar al empleador un daño patrimonial, o bien, un daño que no sea material o cuantificable en dinero ${ }^{40}$, que igualmente puede irrogar un daño económico indirecto o potencial, según veremos ${ }^{41}$; p. ej. daño de imagen, buen nombre o prestigio ${ }^{42}$ o de daño moral ${ }^{43}{ }^{44}$ a la empresa o a otros trabajadores de ésta ${ }^{45}$.

Sobre la relevancia del perjuicio económico para configurar la gravedad del incumplimiento es posible distinguir dos criterios jurisprudenciales: el de aquellos que sostienen que de no existir perjuicio de esta naturaleza un incumplimiento contractual no podría ser grave, y aquel que sostiene que el daño patrimonial no sería un requisito indispensable para configurar la gravedad. No se trata de una disparidad de pareceres que provenga de notables diferencias en los hechos respecto de los que se pronuncian las sentencias. Por el contrario, frente a casos similares existen pronunciamientos divergentes. Es precisamente esta ausencia de un criterio jurisprudencial uniforme la que hace conveniente sistematizar los fundamentos de tales resoluciones y examinar en forma detenida el razonamiento jurisprudencial acerca de la importancia que cabría atribuir al perjuicio económico en cada caso. Es posible que de este examen surjan algunos elementos que faciliten una unificación de criterios y que contribuyan a limitar la resolución, en ocasiones contradictoria, de hechos muy parecidos. En las siguientes líneas procederemos a examinar las diferentes opiniones que existen en esta materia.

\footnotetext{
39) CS 4-12-2008, rol 6072-2008.

40 Guerrero Ostolaza, Jose Maria. "La desobediencia e indisciplina en el trabajo", en: Gil y Gil, José Luis; Del Valle, José Manuel (Coords.). El despido disciplinario, Homenaje al Profesor Juan Antonio Sagardoy B. Madrid, Espańa: Ediciones Cinca, 2009, p. 143.

41 García Viña, Jordi. La Buena Fe en el Contrato de Trabajo. Especial referencia a la figura del trabajador. Madrid, España: Consejo Económico Social, 2001, pp. 172 y 173.

42 CS 28-01-2009, rol 7676-08 y CS 11-07-2002, rol 1899-2002.

43 Poquet Catalá, Raquel. La actual configuración del poder disciplinario empresarial. Valencia, Espańa: Tirant Lo Blanch, 2011, p. 194.

44 Dańo moral debe entenderse en el sentido de un agravio que afecta derechos inherentes a la personalidad. Si bien puede tener consecuencias patrimoniales éstas serían indirectas Fueyo Laneri, Fernando. Cumplimiento e incumplimiento de las obligaciones. Santiago, Chile: Editorial Jurídica de Chile, 1991, p. 365.

45 Martín Valverde, Antonio. Rodríguez-Sañudo Gutiérrez, Fermín; García Murcia, Joaquín, op. cit. (n. 14), p. 707.
} 


\subsubsection{El perjuicio económico es un requisito para la configuración de la gravedad}

Una parte de la jurisprudencia considera que para que el incumplimiento contractual sea grave debe producir perjuicio de tipo económico o pecuniario a la contraparte ${ }^{46}$. De manera que sólo se configuraría la gravedad cuando se ha probado que la conducta del trabajador ha ocasionado al empleador un perjuicio de esta naturaleza.

En este sentido se ha señalado que no es suficiente que el contrato de trabajo contenga una cláusula que establezca que constituye falta grave una conducta determinada del trabajador como puede ser p. ej. no entregar una boleta-, sino que debe demostrarse que el perjuicio causado con motivo de dicho incumplimiento, ha sido de tal entidad que produjo un quiebre en la relación laboral ${ }^{47}$.

En materia de impuntualidad reiterada del trabajador, una parte de la jurisprudencia ha minimizado su importancia al señalar que los atrasos "no serían de la gravedad como para producir un perjuicio a la demandada"48. También se consideró que no existiría tal gravedad en el caso de una vendedora que "llegó atrasada a su trabajo en forma reiterada en el mes de abril de 2004, cuyo promedio fue de media hora diaria" porque no se probó que tal atraso "hubiere causado perjuicio a la empleadora" ${ }^{\prime \prime}$. Es decir, no se ha admitido la existencia de un incumplimiento contractual grave sobre la base de la supuesta inexistencia o falta de prueba de daño patrimonial. Lo que, además de importar elevar la consideración de este factor como un requisito imprescindible para la gravedad, se traduce en desconocer la evidente perturbación -con consecuencias económicasque en general implica el incumplimiento de su jornada por parte de un trabajador ${ }^{50}$.

Buena manifestación de esta tendencia jurisprudencial corresponde a aquellas sentencias que frente a una conducta esencialmente contraria a la fidelidad contractual, como lo sería la sustracción de propiedad del empleador, se han centrado en el daño patrimonial que ésta pudo haber producido, desechando la existencia de gravedad cuando el perjuicio es considerado escaso ${ }^{51}$. Claro ejemplo las mismas es el caso de una dependiente de supermercado que al retirarse de su lugar de trabajo fue sorprendida llevando un producto avaluado en la suma de $\$ 399$. No obstante que fue condenada por el juzgado policía local como autora de hurto falta, al pronunciarse sobre la apelación deducida en el procedimiento laboral la Corte de Concepción declaró que "la mínima cuantía de las especies del supermercado que la actora portaba consigo al salir del trabajo y ser revisada, aparte de importar perjuicio de alguna consideración para la empresa, no puede ni con

46 CS 13-08-2002, rol 1734-2002; CA Antofagasta 14-06-2002, rol 2.526-2002; CA Antofagasta 09-08-2002, rol 2576, CS 12-11-2002 rol 3511-2002; CA Concepción 26-05-2009, rol 711-2008; CA Iquique 07-01-2009, rol 126-2008 y JLT Antofagasta 24-09-2009, RIT O- 100-2009.

47 CA Santiago, 5-06-2002 rol 4474, CS 3-09-2002 rol 2705-2002

48 CA Santiago 8-06-2001, rol 4828-2000.

49 CA Puerto Montt 21-10-2005 rol 81-2005, CS 27-12-2005 rol 6148-2005.

50 Sin embargo, se debe tener en cuenta que a este respecto no existe un criterio uniforme. En similares circunstancias se ha resuelto que los atrasos reiterados constituyen un caso de incumplimiento grave de las obligaciones contractuales: $8^{\circ}$ JLT Santiago 10-7-2002, rol 5073-2001, CA 9-7-2003, 5156-2002, CS 1-10-2001, 3508-2003; JLT Arica rol 11074, CA Arica 27-12-2002 rol 1196-2002, CS 12-3-2003, 571-2003; $8^{\circ}$ JLT 30-5-2001 rol 6691-1998, CA Santiago 15-7-2002, rol 4180-2001, CS 27-11-2002, rol 33132002 y CA Santiago 5-5-1998 rol 45-1998 y CS 17-8-1998, rol 1801-1998, porque entorpecen la actividad de la empresa "sin que sea necesario acreditarse esto último", CS 11-10-2007, rol 599-2007. Esta jurisprudencia no exigiría prueba de perjuicio porque parece considerar evidente la perturbación que se produce en la marcha de la empresa.

51 Esta es precisamente una de las materias respecto de las que existen decisiones divergentes, puesto que, como se verá más adelante, ante infracciones a la fidelidad contractual los tribunales también se han pronunciado acerca de la improcedencia de la exigencia de un perjuicio económico para configurar la gravedad del incumplimiento. 
Enrique Munita Luco / El perjuicio económico como elemento de configuración de la gravedad del despido

mucho elevarse a la consideración de importancia que significa privar a un trabajador de su medio de vida" 5253 .

Con todo, en algunos casos a la existencia de daño económico, se añade el requerimiento de que se trate de uno "importante" 54 . La jurisprudencia ha extremado así la exigencia del perjuicio: no sólo se ha impuesto al empleador la prueba del daño, sino que ha requerido que a su vez éste sea de gran magnitud. En estas situaciones, la cuantía del daño queda sujeta a una apreciación subjetiva que depende en gran medida de la clase de empresa de que se trata y el concepto que tenga el tribunal acerca de su capacidad patrimonial y las consecuencias económicas adversas que ha sufrido como efecto del incumplimiento contractual.

Un ejemplo ilustrativo consistió en un caso de un ejecutivo bancario respecto del cual se tuvo por establecido que infringió cláusulas contractuales y normativa interna de la empresa referidas a la confirmación de la veracidad de datos de clientes y que con su negligencia ocasionó daño patrimonial a la institución financiera, se consideró injustificado su despido, a pesar de acreditarse "un perjuicio de alrededor de \$15.000.000, [ya que] este atendido el activo del Banco resulta a todas luces ínfimo" 55 .

Los criterios antes expuestos no nos parecen del todo acertados pues implicarían valorar la falta principalmente sobre la base del nivel de perjuicio económico ocasionado por ésta, sin considerar otro factor de mayor trascendencia como lo es el incumplimiento mismo de la obligación. Como se advierte, esta exigencia de una relación directa entre incumplimiento grave y un perjuicio económico que el tribunal considere relevante, sitúa la discusión sobre la procedencia del despido no en las circunstancias propias del despido -es decir, en si existe o no incumplimiento laboral-, sino más bien, en sus consecuencias -el perjuicio-, de modo que para este criterio jurisprudencial primaría más allá de cualquiera consideración ética o jurídica, un elemento cuantitativo-económico basado en la magnitud del daño sufrido por este último.

En este mismo sentido se debe tener en cuenta que las diversas causales de extinción del la relación contractual que contempla el artículo $160 \mathrm{CdT}$ no requieren, por regla general, la existencia de perjuicio económico para su configuración. Si bien se trataría de diversas formas de incumplimiento contractual, sólo en el caso del $\mathrm{N}^{\circ} 6$ de esta disposición se incluye dentro de las condiciones para su procedencia que exista "perjuicio material" al empleador ${ }^{56}$. Todas las demás causales, incluyendo la del $\mathrm{N}^{\circ} 7$, no consideran este requisito. La Corte Suprema ha afirmado "que la exigencia de un perjuicio para la demandada" es "extraña a los presupuestos de precepto en estudio" ${ }^{57}$. De esta manera cabría afirmar que cuando el legislador ha estimado que el daño patrimonial debe ser un elemento esencial para la aplicación de una de ellas lo ha señalado en forma expresa y que, en consecuencia, cuando se omite toda referencia a tal requisito no cabría elevarlo a tal condición. En todo caso, ello no implica que el perjuicio económico no deba ser considerado

\footnotetext{
52 JLT Concepción 20-06-2003, Rol 3887, CA Concepción 22-10-2003, rol 2704-2003, CS 8-03-2004, rol 5147-03.

53 Por esta razón se ha sostenido que la sustracción de $\$ 15.000$ no produciría a la empresa "un perjuicio cierto y económico en su patrimonio": $9^{\circ}$ JLT de Santiago, CA Santiago de17-05-2002, rol 3449-2001, CS 28-08-2002, rol 2468-2002). Igualmente que el mal uso de un vale de radio taxi por la suma de $\$ 9.700$ aproximadamente no constituye un incumplimiento grave "dada la ínfima cantidad usada indebidamente" CA Santiago 09-06-2010 Rol 12.242-2008.

54 CA Concepción 27-05-2009, rol 462-08.

55 CA Concepción 13-11-2007, rol 264-2007.

56 Esta causal se refiere a "El perjuicio material causado intencionalmente en las instalaciones, maquinarias, herramientas, útiles de trabajo, productos o mercaderías".

57 CS 18-10-2010, rol 1722-2010 y CS 18-10-2010, rol 1723-2010.
} 
en la valoración judicial de la configuración de la gravedad del incumplimiento, sino que éste debería ser apreciado, según las circunstancias del caso, como un antecedente más y no como un aspecto central de dicho proceso evaluativo.

Es interesante que la única disposición del Código del Trabajo que define expresamente un hecho constitutivo de incumplimiento grave, no establece el perjuicio como requisito para su configuración. Se trata del artículo 140 CdT, relativo al contrato de los trabajadores portuarios eventuales y que señala que constituye incumplimiento grave de las obligaciones que impone el contrato "el atraso en que incurra el trabajador en la presentación a las faenas". Basta acreditar un hecho objetivo y fácil de determinar para que se tenga por establecido el incumplimiento contractual grave.

\subsubsection{El perjuicio económico no es un requisito para la configuración de la gravedad 58}

En casos similares a los anteriores, otra parte de la jurisprudencia considera que el perjuicio económico no puede ser considerado un elemento determinante para la configuración de la gravedad del incumplimiento de las obligaciones que impone el contrato. Le otorga más importancia a otros aspectos de la conducta del trabajador que a las consecuencias perjudiciales de la misma en el patrimonio del empleador. Para esta jurisprudencia la existencia del daño sería irrelevante o al menos secundaria para la calificación de la gravedad.

A partir de este criterio jurisprudencial es posible apreciar ciertas categorías de infracciones respecto de las cuales la jurisprudencia ha sostenido no correspondería la exigencia de perjuicio económico como requisito para la configuración de la gravedad:

A) Infracciones a la buena fe contractual (que afectan a la empresa).

Ello sucede especialmente en caso de transgresión a la buena fe contractual, que es considerada una causa genérica que permite sancionar al trabajador que ha incurrido en diversas clases de conductas reprochables. En su presencia no aparece como necesario que la actuación del trabajador produzca perjuicio efectivo o siquiera que exista dolo o voluntad consciente de producir daño ${ }^{59}$. De esta manera se protegen los intereses materiales e inmateriales del empleador incluso ante situaciones de peligro $^{60}$.

Bastaría la infracción a los deberes de fidelidad y lealtad del trabajador, que forman parte del denominado contenido ético-jurídico del contrato de trabajo, para que se produzca un grave incumplimiento del mismo ${ }^{61}$. Sería intrascendente el resultado de la acción, el daño económico producido al empresario o a su empresa o el provecho obtenido por el trabajador ${ }^{62}$. La jurisprudencia ha aplicado reiteradamente este criterio. Se ha fallado así que el contrato de trabajo se encuentra marcado por un contenido ético que implica que, de conformidad al artículo 1546 del Código Civil, las partes deben cumplir sus obligaciones de buena fe, constituyendo la infracción

\footnotetext{
58 Desde la perspectiva del derecho comparado es posible apreciar que en el derecho de los Estados Unidos, tratándose de las causas disciplinarias como justa causa de despido, como regla general no es necesario que el empresario pruebe que la conducta del trabajador le causó daño. Cfr. Martínez Girón, Jesús. El despido en el Derecho de los Estados Unidos. Madrid, España: Civitas, 1988, p. 75. Por su parte, en esta misma materia, en el derecho francés se ha resuelto que el "grado de gravedad de la falta no depende de la existencia de perjuicio para la empresa" Ретіт, François, op. cit. (n. 24), p. 611.

59 Martín Valverde, Antonio. Rodríguez-Sañudo Gutiérrez, Fermín; García Murcia, Joaquín, p. 706.

60 Castińeira Fernández, Jaime. Prohibición de competencia y contrato de trabajo. Madrid, España: Ministerio del Trabajo, 1977, p. 12.

61 Thayer Arteaga, William; Novoa Fuenzalida, Patricio, op. cit. (n. 5), tomo II, pp. 397-400.

62 Conde Marín, Emilia. La Buena fe en el contrato de trabajo. Madrid, España: La Ley, 2007, p.387.
} 
de tal deber un quiebre de tal entidad que amerita que el empleador ponga unilateralmente término al contrato de trabajo ${ }^{63}$. En este contexto, se sostiene que los deberes de fidelidad y lealtad están estrechamente vinculados con la confianza que se deposita en el trabajador, la cual se infringe cuando existe abuso de confianza y que para su apreciación no es tanto lo que importa el monto del posible daño, sino la conducta antiética del trabajador ${ }^{64}$.

Como se advierte, conforme este criterio jurisprudencial los resultados de dicha conducta tienen escasa trascendencia para valorar el incumplimiento porque lo esencial no es el daño causado, sino la infracción de los deberes de buena fe y de lealtad de parte del trabajador. Como los daños sufridos por el empleador no son una causa, sino una consecuencia, no podrían situarse al mismo nivel de la transgresión a la buena fe como factor determinante de la gravedad del incumplimiento contractual ${ }^{65}$. De este modo, la gravedad no depende de la existencia de un daño directo o inmediato a su empleadora, ya que el mismo sólo reafirma la certeza del incumplimiento contractual, dejando en evidencia el resultado de su falta de fidelidad ${ }^{66}$.

Así, pues, en casos de apropiación de propiedad del empleador, la óptica cuantitativa aparece como una línea errada para solucionar este tipo de controversias. Y es que implicaría "admitir que es tolerable que un trabajador sustraiga especies de su empleador siempre que sean de poca monta (...) No puede el derecho laboral amparar o legitimar conductas que en general el sistema jurídico reprueba", como tampoco obligar "al empleador a mantenerse vinculado con un trabajador que le ha sustraído especies" ya que es "inconveniente mantener una relación que cuya confianza ha sido destruida o gravemente afectada" por el comportamiento del trabajador ${ }^{67}$.

Este criterio se ha aplicado aun en aquellas situaciones en que el perjuicio económico ocasionado a la empresa ha sido escaso. En el caso de un ayudante de bodega que fue sorprendido retirando de la empresa dos botellas de aceite vegetal, la Corte Suprema concluyó que "se acreditó suficientemente que el actor incumplió con los deberes de cuidado, corrección social, fidelidad y lealtad que le imponía su contrato de trabajo". Agregó que "tal infracción debe calificársele de grave" ya que "independientemente del monto del posible daño, la conducta del trabajador resultó contraria a dicha ética" 68 .

Utilizando este mismo criterio, se consideró que un dependiente farmacéutico quebrantó la lealtad y confianza recíproca cuando, sin perjuicio para la empresa, recibió el dinero de un cliente pagó al contado y después hizo figurar la venta como al crédito, que fue pagado con posterioridad, desconociéndose la utilización que hizo del dinero pagado por el cliente en el tiempo intermedio ${ }^{69}$.

Se ha estimado como contrario a la buena fe y por ello un grave incumplimiento contractual el que, en forma reiterada, trabajadores se ausenten injustificadamente de sus labores durante dos días en el mes, sin que se configure la causal del artículo $160 \mathrm{~N}^{\circ} 3$ del CdT por no tratarse de días consecutivos ${ }^{70}$.

Un supuesto especial de infracción a la buena fe contractual tiene que ver con casos de concurrencia desleal. La competencia con la empresa con la que se mantiene una relación labo-

\footnotetext{
CS 28-01-2009, rol 7676-2008; CS 07-05-2009, rol 1028-09; CS 04-06-2009, rol 951-2009 y CS 02-01-2012, rol 2512-2011.

64 CA Iquique 3-9-2007, rol 69-2007.

65 García Viña, Jordi, op. cit. (n. 41), p. 171.

66 CS 17-10-2007, rol 4560-2006.

67 CA Concepción 28-11-2007, rol 319-2007.

68 CS 05-03-2009, rol 7789-2008.

69 CS 28-01-2009, rol 7676-2008.

70 CS 13-06-2013, rol 1242-2013.
} 
ral vigente implica un abuso de confianza y quebrantamiento de la fidelidad y lealtad debidas al empleador ${ }^{71}$. Aquellos que se desempeñan para una empresa y conocen información confidencial acerca de las condiciones que ofrece a quienes contratan con ella-clientes o proveedores-compiten con una ventaja indebida.

La obligación de lealtad y prohibición de competencia desleal debiesen siempre entenderse incluidas en el contrato de trabajo. Sin embargo, el $\mathrm{N}^{\circ} 2$ del artículo $160 \mathrm{CdT}$ que se refiere a las "Negociaciones que ejecute el trabajador dentro del giro del negocio", agrega como requisito para su aplicación "que hubieren sido prohibidas por escrito en el respectivo contrato". Esto ha sido entendido como un "error en la redacción de la causal [que] venía ya del Código de 1931" porque lo que debería constar por escrito es justamente lo contrario, vale decir, la autorización para que el trabajador realice negociaciones en el giro del negocio y no su prohibición, ya que esta última emana de la naturaleza del contrato ${ }^{72}$. En todo caso, la jurisprudencia ha utilizado un criterio más amplío y, en circunstancias de competencia con la propia empresa, ha admitido la aplicación de la causal de incumplimiento grave de las obligaciones que impone el contrato, (artículo $160 \mathrm{~N}^{\circ} 7$ $\mathrm{CdT}$ ) independientemente de la existencia de una prohibición expresa, evitándose así las restricciones de la norma en comento $^{73}$.

La concurrencia desleal es un caso particular de infracción a la buena fe que permite fundar el despido en un grave incumplimiento contractual, incluso si no se produce daño efectivo a la empresa, ya que a su respecto basta el daño potencial ${ }^{74}$. Se determinó así que un Director Zonal de la Corporación de Asistencia Judicial que, durante su horario laboral, asistía a diligencias judiciales particulares quebrantó sus deberes de lealtad y buena fe en forma tal que justifica la terminación de su contrato de trabajo ${ }^{75}$. La mera realización de actos preparatorios de una competencia desleal sería suficiente ${ }^{76}$. Esto ocurriría en caso de constituirse una sociedad destinada a desarrollar la misma actividad comercial de su empleadora ${ }^{77}$. La sola existencia de perjuicio potencial constituiría razonable y justificado límite a las libertades constitucionales de industria y trabajo ${ }^{78}$.

\section{B) Daño potencial}

No siempre se requiere un daño actual y efectivo, sino que basta uno potencial. Esto es, sólo una amenaza de esta clase de daños ${ }^{79}$. Dentro de este apartado pueden incardinarse, entre otros, supuestos de incumplimientos de deberes contractuales o reglamentación interna de la empresa,

\footnotetext{
71 Dieguez, Gonzalo. La fidelidad del Trabajador en LCT. Pamplona, España: Ediciones Universidad de Navarra, 1969, pp. 63 y ss.

72 Thayer, William; Novoa, Patricio, op. cit. (n. 5), tomo 3, p. 52.

73 El artículo 331 del Código de Comercio relativo a los factores y dependientes de comercio demuestra que el rechazo a la competencia desleal es un principio que informa nuestro derecho en forma aún más amplia que el derecho laboral. En este sentido seńala: "Se prohíbe a los factores y dependientes traficar por su cuenta y tomar interés en nombre suyo o ajeno en negociaciones del mismo género que las que hagan por cuenta de sus comitentes, a menos que fueren expresamente autorizados para ello.

${ }^{\mathrm{P}}$ or el hecho de contravenir a esta prohibición, se aplicarán al comitente los beneficios que produzcan las negociaciones del factor o dependiente, quedando las pérdidas de cargo exclusivo de ellos".

74 Montoya Melgar, Alfredo, op. cit. (n.16), p. 470.

75 CS 22-06-2009, rol 2319-2009.

76 Albiol Montecinos, Ignacio; Camps Ruiz, Luis Miguel; López Gandía, Juan; Sala Franco, Tomás, op. cit. (n. 30 ), p.582.

77 CA Santiago 13-07-2001, rol 3698-2001; CS 29-10-2009, rol 6139-2009.

78 López Aniorte, María del Carmen. "Competencia desleal y calificación del despido”, en: Aranzadi Social. Tomo V, España, Madrid, 1997. También en Domblas María Asunción; Fernández Baraibar, Maite. Causas del Despido Disciplinario. Vol. II. Pamplona, España: Thomson Aranzadi, 2007, p. 219.

79 CA Concepción 30-8-2006, rol 2445-2006; CS 31-10-2006, 5138-2006.
} 
tales como la tentativa de competencia desleal, conductas que afecten negativamente la imagen comercial del empleador o que constituyan una amenaza de un daño patrimonial para éste, todos los cuales podrían constituir un perjuicio -que no se ha materializado pero que existe una importante posibilidad de que ocurra-, o bien, que está latente la posibilidad que este suceda en un futuro, como podría serlo el riesgo de pérdida de clientela o quedar la empresa expuesta al fraude ${ }^{80}$.

- Daño a la imagen del empleador

Dentro de las obligaciones que se desprenden de la naturaleza del contrato de trabajo se encuentra el deber del trabajador de no actuar en perjuicio de su empleador, aún cuando no exista un daño inmediato ${ }^{81}$. El daño a la imagen de la empresa influye en la trascendencia de un incumplimiento $^{82}$. Como se verá, conductas que impliquen un grave detrimento de aspectos tales como la imagen comercial o prestigio de su empleador podrían justificar suficientemente la terminación del contrato de trabajo ${ }^{83}$.

Ejemplo de lo anterior se observa en la actuación del secretario tramitador de un abogado que no le informaba oportunamente de las causas que se encontraban en tabla para su vista en la Corte, lo que impidió que este pudiera alegarlas. Se declaró que el abogado sufrió un daño que le afecta en "su ámbito profesional, menoscabando su imagen y privándola de atributos como son la seriedad y la responsabilidad" $"$. De la misma manera se consideró grave la conducta de un aspirante a maestro de casino que fue sorprendido probando directamente de la olla con el cucharón y devolviendo los restos de comida a la misma. El tribunal tuvo especialmente en cuenta el perjuicio a la imagen de la empresa que tiene por giro el suministro de alimentos en empresas, colegios y otras instituciones ${ }^{85}$. El mismo razonamiento se tuvo respecto del dependiente de una Isapre que procedió a la afiliación de una persona con documentos con firmas falsas, ya que se concluyó que afectó "la imagen de su empleadora ante los clientes" 86 . Lo mismo sucedió respecto de un vendedor de automóviles que tomó un vehículo de un cliente "para pasear en él", chocando por su descuido con otro automóvil en el que resultaron lesionados tres menores, sin que se produjera un perjuicio económico relevante porque existían seguros contratados ${ }^{87}$. En todos estos casos existió un daño a la imagen del empleador que podría derivar en un potencial daño económico, puesto que se afecta su prestigio con el consecuente riesgo de pérdida de clientela.

- Incumplimiento de la normativa interna.

El poder de dirección del empleador se traduce, entre otras cosas, en que la empresa puede emitir normas internas ${ }^{88}$ que, dentro de ciertos supuestos de legitimidad, obligan al trabajador ${ }^{89}$. Su infracción facultaría al empleador para aplicar sanciones que, dependiendo de su gravedad, pueden llegar incluso al despido del infractor. En estas circunstancias cabría cesar el contrato por

\footnotetext{
80 CA Concepción 08-11-2006, rol 2706-2005, CS 18-01-2007, rol 104-2007.

81 CS 18-10-2010, rol 1723-2010.

82 Poquet Catalá, Raquel, op. cit. (n. 43), p. 196.

83 Albiol Montecinos, Ignacio. "Despido Disciplinario", en Albiol Montecinos, Ignacio (Dir.). Extinción del Contrato de Trabajo. Valencia, Espańa: Tirant Lo Blanch, 2011, p. 920.

84 CA San Miguel 05-12-2002, rol 289-02, CS 18-03-2003, rol 70-03.

85 CA Concepción 08-11-2006, rol 2706-2005, CS 18-01-2007, rol 104-2007.

86 CS 05-10-2012, rol 1721-2012.

87 CS 11-10-2005, rol 2418-2004.

88 Alonso Olea, Manuel; Casas Baamonde, María Emilia, op. cit. (n. 11), p. 427.

89 Se deben tener en cuenta las limitaciones derivadas de la dignidad y derechos de los trabajadores, tales como aquellas indicadas en los artículos 2, 5, 153 inciso $4^{\circ}, 154$ inciso final, etc.
} 
grave incumplimiento contractual puesto que el trabajador no sólo se obliga a ejecutar el trabajo pactado sino que hacerlo en la forma y modo que se determine por el empleador ${ }^{90}$.

Sin que necesariamente se requiera la concreción de perjuicio económico, o siendo su consideración más bien secundaria, se ha estimado que habría grave incumplimiento del contrato de trabajo en caso infringirse por parte de un trabajador la normativa interna de la entidad empleadora en materias de importancia para la empresa ${ }^{91}$, como por ejemplo en el caso de las normas relativas a conflictos de interés ${ }^{92}$. Esto ha ocurrido especialmente en el caso de los trabajadores del ámbito financiero que, pese a haberse obligado contractualmente a no hacerlo, han incurrido en incumplimientos comerciales ${ }^{93}$. La empresa se encontraría expuesta a un daño potencial, que no ha llegado a materializarse. No obstante ello se ha estimado que esta circunstancia justificaría la terminación del contrato por un grave incumplimiento del trabajador ${ }^{94}$.

Por esta razón se ha declarado que un trabajador incurre en grave incumplimiento contractual al infringir "las normas y procedimientos para el despacho y facturación de las mercaderías" 95 . Igual declaración se formuló respecto de un ejecutivo bancario que no cumplió los requisitos y condiciones para dar curso a solicitudes de crédito, como tampoco las normas de la Superintendencia de Bancos para operaciones de crédito ${ }^{96}$ y en el de otro ejecutivo que infringió los reglamentos del banco al abrir una cuenta a una persona que no podía hacerlo ${ }^{97}$. Asimismo se declaró que pedir prestado a clientes del banco, aún sin perjuicio para éste, implica un grave incumplimiento contractual ${ }^{98}$. Lo mismo ocurrió en el caso de un vendedor de una multitienda que irregularmente permitió a dos compradores participar en una promoción para la que no reunían los requisitos ${ }^{99}$.

De la misma manera se ha considerado de gravedad que un trabajador infrinja el Código de Ética de una empresa, asumiendo un cargo de elección popular que de acuerdo a dicha normativa, conocida por el dependiente, resultaba incompatible con la vigencia de su contrato de trabajo ${ }^{100}$.

Una categoría a la que se asigna especial importancia corresponde a la infracción de prohibiciones contenidas en el Reglamento Interno de Orden, Higiene y Seguridad relacionadas con la seguridad de las personas y de los bienes de la empresa. Se consideró un grave quebrantamiento contractual el que trabajadores que se desempeñan como conductores de camiones se presenten al trabajo en estado de intemperancia "pues tal conducta, resulta contraria a la de un conductor de un vehículo de dicha magnitud, con el consiguiente riesgo no sólo para él sino también para terceros así como de los bienes de su empleador" ${ }^{\prime 01}$. Sobre el mismo aspecto en análisis, se ha dicho que es grave el hecho en que incurrió un de "conductor de grúa que debía desempeñar, las maniobras

\footnotetext{
90 SÁnchez-Rodas Navarro, Cristina. "La indisciplina y la desobediencia como causas de extinción del contrato de trabajo", en: Castiñeira Fernández, Jaime. Presente, pasado y futuro de la regulación del despido. Pamplona, España: Aranzadi, 1997, p. 419.

91 CS 11-11-2009, rol 6611-2009 y CS 24-08-2005, rol 717-2005.

92 CS 16-10-2000, rol 2809-2000.

93 CS 11-07-2002, rol 1899-2002 y CA Talca 25-03-2010, rol 25-03-2010.

94 CS 18-10-2010, rol 1722-2010; CS 18-10-2010, rol No 1723-2010 y CA Arica 12-10-2011, rol 32-2011.

95 CS 12-06-2003, rol 1436-2003.

96 CA Santiago, 29-10-2003, rol 6587-2002, CS 4-3-2004, rol 5391-2003.

97 CS 16-12-2004, rol 5414-2004.

98 CA Valdivia, 29-5-2002 rol 1565 2002, CS 9-9-2002 rol, 2451-2002.

99 CS 07-05-2009, rol 1028-2009.

100 CS 29-05-2012, rol 8513-2011.

101 CS 02-12-2011, rol 2230-2011.
} 
peligrosas que realizó bajo la influencia del alcohol el día de los hechos y que, con ello, puso en riesgo no solo su integridad física sino la de sus demás compañeros de trabajo" ${ }^{102}$.

- Perjuicio a compañeros de trabajo.

Existen situaciones en las que, pese a no existir un daño directo al empleador, se ha considerado que existe incumplimiento grave porque se ha producido un perjuicio, sea o no económico, a un compañero de trabajo.

El CdT contempla causales de término del contrato de trabajo que se refieren de manera directa a actuaciones de un trabajador en desmedro de otro u otros dependientes de la empresa, como lo son por ejemplo el acoso sexual o las vías de hecho (artículo $160 \mathrm{~N}^{\circ} 1 \mathrm{CdT}$ letras b) y c) respectivamente). El CdT contempla una solución semejante frente a la vulneración de los derechos fundamentales de un trabajador por parte de otros dependientes de la empresa y que es tolerada por esta, puesto que puede ser condenada como infractora de tales derechos ${ }^{103}$. Por esta razón frente a un caso de discriminación religiosa respecto de una persona que profesaba la religión musulmana, entre otras medidas, el tribunal dispuso la capacitación de todo el personal de la empresa para lograr "un trato respetuoso entre pares y subordinados" especialmente en lo referido a evitar actos de discriminación ${ }^{104}$. A partir de ello es posible concluir que el deber de protección que obliga al empleador también se extendería a proteger al trabajador respecto de los otros trabajadores de la empresa. Los trabajadores deben abstenerse de conductas lesivas a los derechos de otros ya que, al actuar de otra forma infringirían deberes mínimos de convivencia que deben darse en el contexto de la relación laboral, como también su deber de cumplir de buena fe el contrato de trabajo ${ }^{105}$.

Entre situaciones como las descritas podemos destacar casos de robo o hurto entre compañeros de trabajo, utilización de datos personales con miras a la obtención de beneficios que pertenecían a otro trabajador, o alterar las tareas de un par para lograr provechos propios o de terceros. Nuestra jurisprudencia consideró así como justificados los despidos -y por tanto sin derecho a indemnizaciones por cese de contrato- de trabajadores que incurrieron en los siguientes conductas: a) uso indebido de tarjetas de crédito que pertenecían a un compañero de labores y se encontraban en el interior de la billetera de propiedad de este último, sustraída en su lugar de trabajo ${ }^{106}$, lo que se consideró por el tribunal como una "falta honestidad en el actuar", que ameritaba un despido sin derecho a las indemnizaciones por término de contrato; b) mal uso de un código de otra trabajadora del local comercial donde, haciendo figurar a su nombre una venta respecto de la cual no ingresó el precio a la caja, con el consiguiente perjuicio para ella, ya que al no ingresar el dinero de la compra, su compañera de labores debía reembolsarlo ${ }^{107}$; c) "al alterar las calificaciones de otro profesor, respecto de dos alumnos, la actora ha faltado a los indicados valores y especialmente al deber de lealtad para con un colega de profesión"108.

Pareciera advertirse una mayor estrictez de los jueces en aquellos casos en que un trabajador actúa en perjuicio de otro dependiente con respecto a aquellos en que la empresa es la

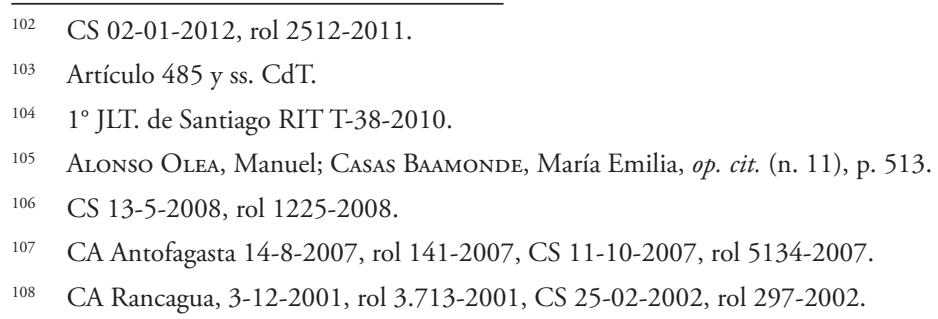


perjudicada. También se le ha mencionado como una agravante ${ }^{109}$. El diferente tratamiento pudiera deberse a que la persona afectada y quien le ocasiona un daño se encuentran en un plano de igualdad, lo que no le permitiría tomar medidas disciplinarias respecto del infractor, como si podría hacerlo la empresa.

\subsection{Casos Particulares EN QUe la EXISTENCIA DE DAÑo ECONÓMiCo NO SE TRADUCE EN INCUMPLIMIENTO GRAVE Y SU FUNDAMENTO}

Existen casos en los que pese a que el incumplimiento de un trabajador provoca un daño en la empresa, esta situación no se concibe como grave, toda vez que aquél no ejecuta las obligaciones que derivan de su contrato por razones ajenas a su voluntad o estando amparado por la ley.

El trabajador podría no cumplir con su prestación de trabajo con motivo del cumplimiento de deberes considerados de mayor rango. Así sucedería en el caso de deberes para con el Estado, la justicia o las autoridades públicas, o bien, de circunstancias que impliquen la protección de un deber jurídico de más alto valor y que tienen, por regla general, primacía sobre los propios deberes laborales. Todos serían casos de inexigibilidad de otra conducta ${ }^{110}$ porque a lo imposible nadie está obligado ${ }^{111}$. No existe así incumplimiento grave en el caso de un dependiente de comercio que estando en funciones cierra el local comercial antes de la hora porque "recibió la llamada telefónica comunicándole el fallecimiento de su padre", concluye la Corte que no podría exigírsele otra conducta ${ }^{112}$.

Existen algunas circunstancias respecto de las cuales nuestro derecho positivo establece expresamente la suspensión del deber de prestar servicios por parte del trabajador. Es decir, no obstante el perjuicio que ello pudiera acarrear a la empresa, se indica que el trabajador no desarrollará las labores para las que fue contratado, suspendiéndose de iure las principales obligaciones que nacen de la relación contractual laboral -la prestación de los servicios y el pago de la remuneración correlativa- como ocurre en el caso de la huelga aprobada dentro de un proceso de negociación colectiva reglada ${ }^{113}$ y el servicio militar.

En ocasiones no se considera casos de incumplimiento grave de las obligaciones que impone el contrato de trabajo la falta de diligencia, la impericia y la ausencia de previsión, aun-

\footnotetext{
109 Conde Marína, Emilia, op.cit. (n. 62), p.387.

110 Barreiro González, Germán. Diligencia y negligencia en el cumplimiento. Madrid, Espańa: Centro de Estudios Constitucionales, 1981, pp. 400-401.

11 La imposibilidad de ejecución que extingue las obligaciones también resulta aplicable a obligaciones de hacer o no hacer y podría deberse a circunstancias tales como la enfermedad y el acto de autoridad Josserand, Louis. Teoría General de las Obligaciones. Santiago, Chile: Editorial Parlamento, 2008, p. 579.

112 CS 06-03-2001, rol N 4569-00.

113 Sin perjuicio del deber del sindicato o grupo negociador de proporcionar el personal indispensable para la ejecución de las operaciones cuya paralización pueda ocasionar un daño actual e irreparable en los bienes materiales de la empresa, pedio o establecimiento o un dańo a la salud de los usuarios de un establecimiento asistencial o de salud o que preste servicios esenciales (artículo 380 del Código del Trabajo).
} 
que de ellas se deriven daños patrimoniales para las empresas ${ }^{114}$. Ello ocurriría por ejemplo en el caso que de un trabajador al se le exija desarrollar una labor para la que evidentemente carece de la capacitación, formación o experiencia requerida. Así, no habría incumplimiento grave "si el empleador no proporcionó al trabajador la información esencial que requería para desempeñar sus funciones, impidiéndole cumplir con sus obligaciones contractuales" 115 . Tampoco se podría considerar un grave incumplimiento contractual el de un trabajador que, con motivo de un accidente laboral, presenta un estado deteriorado de salud que le impide prestar adecuadamente sus servicios contractuales ${ }^{116}$.

Otra muestra de ello sería el caso de un trabajador que, con motivo de aplicar un procedimiento o práctica aceptados por la empresa, ocasiona un perjuicio a esta última. Así en el caso de una cajera que pagó tres cheques girados por el jefe de operaciones de la oficina bancaria en que ella se desempeñaba y que correspondían a una cuenta corriente en un banco distinto, si bien se admitió que ello no era lo que correspondía hacer, en la práctica ello era aceptado por el banco y de esta forma no habría incumplido gravemente sus obligaciones contractuales, con independencia del daño que se pudo ocasionar ${ }^{117}$.

En el caso de trabajadores de una estación de servicio que no siguieron el procedimiento para el pago de ventas con cheques, consistente en registrar el número de teléfono, de documento de identidad y de patente del vehículo de los compradores, se consideró que no existió de gravedad en su incumplimiento, aun cuando los cheques resultaron impagos, ya que ello no sería atribuible a la omisión de dicho procedimiento sino que a quienes giraron los cheques, esto es, terceros ajenos a la relación contractual ${ }^{118}$.

\section{FACTORES QUE DETERMINAN LA IMPORTANCIA QUE SE OTORGA AL PERJUICIO EN LA CALIFICACIÓN DE LA GRAVEDAD}

Según se ha visto, el examen para determinar la gravedad del incumplimiento debería centrarse fundamentalmente en la conducta -acción u omisión- infractora y no en el daño que esta pueda provocar. Esto porque el perjuicio económico carecería de la importancia que en muchas ocasiones pareciera asignársele, ya que es sólo una manifestación o consecuencia del incumplimiento y no una causa del mismo.

Un antecedente que permite efectuar tal afirmación lo constituyen las numerosas situaciones en las que la configuración de la gravedad no estaría determinada por la presencia de daño económico al empleador, tal como ocurre en los casos de infracción a la buena fe contractual. El trabajador tiene la obligación de guardar fidelidad a su empleador para no defraudar la confianza depositada a su respecto ${ }^{119}$. De ello se sigue que al infringirse este deber no es la cuantía del daño que pudo existir lo que caracteriza o agrava la falta puesto que no cabe distinguir grados de

\footnotetext{
114 Alonso García, Manuel. Curso de Derecho del Trabajo. Sexta edición. Barcelona, España: Ariel, 1980, p. 560.

115 CS 01-06-2006, rol 5985-2005.

116 CA Punta Arenas 13-08-2007, rol 18-2007.

117 CS 27-03-2003, rol 3595-2002.

118 CS 31-08-2009, rol 3983-2009.

119 Alonso García, Manuel, op. cit. (n. 114), pp. 559 y 560.
} 
pérdida de confianza ${ }^{120}$. En consecuencia, para la determinación de la gravedad, no cabría aplicar una valoración gradualista del incumplimiento pues la confianza no admite grados ni matices ${ }^{121}$.

No obstante que en las infracciones a la buena fe contractual el perjuicio no podría ser un elemento determinante para establecer la gravedad de la falta, es natural que de alguna manera se le tenga en cuenta porque la conducta depende de varias circunstancias entre las que no debe desconocerse el daño que se pueda producir ${ }^{122}$. Esto sucede, especialmente, en los supuestos de defraudación en el manejo del dinero de la empresa ${ }^{123}$.

Fuera del ámbito de las infracciones a la buena fe contractual, nos parece que el perjuicio económico no sería sino un elemento que, entre otros de mayor relevancia, permitiría concluir que el incumplimiento del trabajador está dotado de la entidad suficiente para considerarlo grave. La importancia del perjuicio para dicha calificación es relativa y depende de las circunstancias de cada caso. Es uno de los factores a considerar en la ponderación de la gravedad ${ }^{124}$. Su concurrencia sólo reafirma la certeza del incumplimiento contractual, dejando patente el resultado del mis$\mathrm{mo}^{125}$. Así, podría considerársele un elemento concurrente para determinar la gravedad, pero no uno indispensable o esencial. En este sentido, se ha resuelto que la conducta en que se fundamente un despido debe ser calificada como grave atendiendo a diversos factores tales como la naturaleza de la labor desarrollada por el trabajador, las circunstancias en que el eventual incumplimiento se produjo, la responsabilidad que le correspondería, los perjuicios que de tal conducta se derivó para su empleador, etc. ${ }^{126}$.

Pareciera que la relevancia que cabría atribuir al daño debiese ser mayor en la medida que la conducta tenga una menor connotación ética, por lo que por ejemplo debiese tomársele más en cuenta en los casos referidos a una actuación negligente del trabajador que en aquellos que signifiquen infracción a la buena fe, en que su consideración sería mínima. En este escenario la gravedad debería ser determinada sobre la base de la entidad del perjuicio ocasionado. Así por ejemplo se desestimó la gravedad de la conducta de un supervisor al que, sin que existiera de su parte infracción a la normativa interna de la empresa, se le atribuyó negligencia por la pérdida de una herramienta por parte de un operario a su cargo, porque la empresa no demostró "los perjuicios concretos que le trajo la pérdida de la máquina" ${ }^{27}$.

Favorecería la relevancia que nuestra jurisprudencia parece asignar al perjuicio como factor para la determinación de la gravedad del incumplimiento, el que los jueces lo utilizarían como un elemento de corrección de las consecuencias excesivas que eventualmente podría tener para un trabajador que se declare que ha incurrido en incumplimiento contractual grave. Como es sabido, nuestro sistema establece que en caso de incurrir un dependiente en esta causal no recibiría indemnización alguna por término del contrato de trabajo. En tanto que, declarado por un tribunal que esta fue injustificadamente invocada por el empleador, la indemnización por años de servicio se incrementaría en un ochenta por ciento.

\footnotetext{
20 Dieguez, Gonzalo, op. cit. (n. 71), p. 29.

121 López Aniorte, María del Carmen, op. cit. (n. 78), p. 220.

122 Dieguez, Gonzalo, op. cit. (n. 71), p. 30.

123 Albiol Montecinos, Ignacio; Camps Ruiz, Luis Miguel; López Gandía, Juan; Sala Franco, Tomás, p.581.

124 García Viña, Jordi, op. cit. (n. 41), p. 171

125 CS 17-10-2007, rol 4560-2006.

126 CA Valdivia 27-8-2002, rol 1629-2002; CS 20-1-2003, rol 3810-2002 y CS 13-8-2002, rol 1734-2002.

127 CA Concepción 3-10-2005, rol 5718-2003, CS 22-05-2006, rol 5825-2005.
} 
Muchas veces los jueces atienden a consideraciones tales como la antigüedad del trabajador o escasa entidad del perjuicio para limitar la declaración de existencia de un grave incumplimiento $^{128}$. De esa manera se trata de evitar que el dependiente no reciba indemnización alguna como consecuencia de la declaración de justificación de la causal aplicada. En dicho contexto circunstancias tales como la inexistencia, falta de prueba, o bien, escasa cuantía del daño patrimonial sirven de base para evitar la declaración de existencia del grave incumplimiento.

Como resultado de este criterio jurisprudencial sucede que, ante claros quebrantamientos de deberes del trabajador, los jueces se muestran más bien reacios a admitir la gravedad del incumpliendo invocado por el empleador para cesar la relación laboral. Ello pese a la existencia de infracciones contractuales que presentan características de seriedad y relevancia que permitirían sostener una pérdida de confianza que justificaría la extinción del contrato de trabajo.

Si bien en ciertos casos podría aparecer como un castigo desproporcionado que el dependiente no reciba indemnización alguna, no lo es menos para el empleador que, a pesar de producirse un incumplimiento contractual serio, se vea obligado a pagar la indemnización por término de contrato aumentada en la forma señalada. A consecuencia de lo anterior, nos parece conveniente revisar la ausencia de alternativas intermedias tales como que, pese que se considere que no existió un incumplimiento de la magnitud que justifique la privación de toda indemnización por término de contrato, se faculte al juez para regularla en un monto menor o bien para declarar improcedencia de aplicar un incremento a su respecto. El otorgarle tal facultad corresponde a una solución que no resultaría ajena a nuestro derecho positivo. En efecto, en materia de acoso sexual se encuentra previsto que, de aplicarse por la empresa el procedimiento de reclamo previsto en el Código, el empleador no podría ser condenado al pago del incremento legal por despido injustificado ${ }^{129} 130$.

Por lo expuesto, ante infracciones de cierta relevancia pero que a juicio del tribunal no permitan justificar privar al trabajador de toda indemnización, nos parece conveniente permitir al juez laboral conceder al trabajador la indemnización por años de servicio excluyendo el incremento previsto en el artículo $168 \mathrm{CdT}$. De esta forma, se permitiría al tribunal resolver cada caso de la manera más adecuada, evitándose soluciones extremas que en muchas ocasiones se alejan de la que aparece como la solución más justa para sus circunstancias particulares.

\section{CONCLUSIONES}

1) No existe uniformidad de criterio en la jurisprudencia sobre la importancia del perjuicio económico provocado a la empresa para la calificación de la gravedad del incumplimiento contractual del trabajador en relación al despido. Encontramos criterios divergentes aun en casos en que los hechos son muy similares.

128 CS 16-09-2010, rol 3775-2010 y CS 08-06-2006, rol 6260-2005.

129 El artículo. 154 del CdT seńala: "El reglamento interno deberá contener, a lo menos, las siguientes disposiciones: 12.- El procedimiento al que se someterán y las medidas de resguardo y sanciones que se aplicarán en caso de denuncias por acoso sexual. En el caso de las denuncias sobre acoso sexual, el empleador que, ante una denuncia del trabajador afectado, cumpla íntegramente con el procedimiento establecido en el Título IV del Libro II, no estará afecto al aumento seńalado en la letra c) del inciso primero del artículo 168, y".

130 Por su parte el artículo.168 del CdT señala en su parte pertinente que: "En el caso de las denuncias de acoso sexual, el empleador que haya cumplido con su obligación en los términos que seńalan el artículo 153, inciso segundo, y el Título IV del Libro II, no estará afecto al recargo de la indemnización a que hubiere lugar, en caso de que el despido sea declarado injusto, indebido o improcedente”. 
2) Incide en la referida calificación no sólo el daño económico directo, sino también el indirecto o el potencial, como asimismo, el daño a compañeros de trabajo. Los jueces suelen ser más estrictos respecto de incumplimiento que afecta a estos últimos. Una explicación posible es que como los involucrados son pares no se aplicarían los criterios de protección (en pro del trabajador despedido) propios del Derecho del trabajo.

3) Resulta más acertada la jurisprudencia que no considera al perjuicio económico como un elemento determinante para la calificación de la gravedad. Ello porque no es parte o causa del incumplimiento sino una consecuencia del mismo. Es la conducta del trabajador la que debe ser objeto de examen y no sus efectos. Esto ocurre especialmente en los casos de infracción a la lealtad y fidelidad debida al empleador.

4) Se aprecian distorsiones en el análisis de la gravedad porque el sistema de indemnizaciones por terminación de contrato de trabajo es muy rígido en cuanto a las alternativas que otorga a los jueces. De lege ferenda, nos parece que deberían otorgarse facultades a los jueces para regular la indemnización por años de servicio y particularmente su incremento en caso de no admitirse la justificación de la causal.

\section{BIBLIOGRAFÍA}

Albiol Montecinos, Ignacio; Camps Ruiz, Luis Miguel; López Gandía, Juan; Sala Franco, Tomás. Derecho del Trabajo. Tomo II. Valencia, España: Tirant Lo Blanch; 2003.

Albiol Montecinos, Ignacio. "Despido Disciplinario”, en Albiol Montecinos, Ignacio (Dir.). Extinción del Contrato de Trabajo. Valencia, España: Tirant Lo Blanch, 2011.

Alcalde Rodríguez, Enrique. “Acción resolutoria y excepción de contrato no cumplido”, en: Actualidad Jurídica, ańo IV, $\mathrm{N}^{\circ}$ 8, Santiago, Chile, julio 2003.

Alonso García, Manuel. Curso de Derecho del Trabajo -6a edición-. Barcelona, España: Ariel, 1980.

Alonso Olea, Manuel; Casas Baamonde, María Emilia. Derecho del Trabajo -24a edición-. Madrid, España: Civitas, 2006.

Barreiro González, Germán. Diligencia y negligencia en el cumplimiento. Madrid, España: Centro de Estudios Constitucionales, 1981.

Barros Bourie, Enrique. "Finalidad y alcance de las acciones y los remedios contractuales", en GuZMÁN Brito, Alejandro (edit.). Estudios de Derecho Civil III, Jornadas Nacionales de Derecho Civil, Valparaíso, 2007. Santiago, Chile: Legal Publishing, 2008.

Castiñera Fernández, Jaime. Prohibición de competencia y contrato de trabajo. Madrid, España: Ministerio del Trabajo, 1977.

Conde Marín, Emilia. La buena fe en el contrato de trabajo. España, Madrid: La Ley, 2007.

Dieguez, Gonzalo. La fidelidad del Trabajador en LCT. Pamplona, España: Ediciones Universidad de Navarra, 1969.

Diez-Picazo, Luis. Fundamentos del Derecho Civil Patrimonial-5a Edición-. Vol. II España, Madrid: Civitas, 1996.

Domínguez Águila, Ramón. La Prescripción Extintiva. Doctrina y Jurisprudencia. Santiago, Chile: Editorial Jurídica de Chile, 2004.

Fueyo Laneri, Fernando. Cumplimiento e incumplimiento de las obligaciones. Santiago, Chile: Editorial Jurídica de Chile, 1991.

García Viña, Jordi. La Buena Fe en el Contrato de Trabajo. Especial referencia a la figura del trabajador. Madrid, España: Consejo Económico Social, 2001. 
Gorelli Hernández, Juan. "Deber de obediencia y despido por desobediencia", en: Revista Española de Derecho del Trabajo No 87/1998. Jurisprudencia. España, Madrid. También en Domblas María Asunción; Fernández Baraibar, Maite. Causas del Despido Disciplinario. Vol. II. Pamplona, España: Thomson Aranzadi, 2007.

Guerrero Ostolaza, Jose Maria. "La desobediencia e indisciplina en el trabajo", en: Gil y Gil, José Luis; Del Valle, José Manuel (Coords.). El despido disciplinario, Homenaje al Profesor Juan Antonio Sagardoy B. Madrid, España: Ediciones Cinca, 2009.

Irureta Uriarte, Pedro P. "La Falta de Probidad como causa de extinción del contrato de trabajo", en: VVAA. Estudios en Homenaje al profesor William Thayer. Santiago, Chile: Sociedad Chilena de Derecho del Trabajo y de la Seguridad Social, Santiago, 1998.

Josserand, Louis. Teoría General de las Obligaciones. Santiago, Chile: Editorial Parlamento, 2008.

Labatut Glena, Gustavo. Derecho Penal. Tomo I. Santiago, Chile: Editorial Jurídica de Chile, 1995.

Larroumet, Christian. Teoría general del contrato. Vol. II. Bogotá, Colombia: Editorial Temis S.A., 1993.

López Aniorte, María del Carmen. "Competencia desleal y calificación del despido", en: Aranzadi Social. Tomo V, España, Madrid, 1997. También en Domblas María Asunción; Fernández Baraibar, Maite. Causas del Despido Disciplinario. Vol. II. Pamplona, España: Thomson Aranzadi, 2007.

Macchiavello, Guido. Derecho del Trabajo. Tomo I. Santiago, Chile: Fondo de Cultura Económica, Santiago, 1986.

Martín Valverde, Antonio. Rodríguez-Sañudo Gutiérrez, Fermín; García Murcia, Joaquín. Derecho del Trabajo. Décimo Quinta Edición. España, Madrid: Tecnos, 2006.

Martínez Girón, Jesús. El despido en el Derecho de los Estados Unidos. Madrid, España: Civitas, 1988.

Messineo, Francesco. Doctrina general del contrato. Tomo II. Buenos Aires, Argentina: Ediciones Jurídicas EuropaAmérica, 1979.

Montoya Melgar, Alfredo. Derecho del Trabajo. Madrid, España: Tecnos, 1999.

Petit, François. El despido disciplinario en Francia, en: Gil y Gil, José Luis; Del Valle, José Manuel (Coords.). El despido disciplinario, Homenaje al Profesor Juan Antonio Sagardoy B. Madrid, España: Ediciones Cinca, 2009.

Poquet Catalá, Raquel. La actual configuración del poder disciplinario empresarial. Valencia, España: Tirant Lo Blanch, 2011.

SÁnchez-Rodas Navarro, Cristina. "La indisciplina y la desobediencia como causas de extinción del contrato de trabajo”, en: Castiñeira Fernández, Jaime. Presente, pasado y futuro de la regulación del despido. Pamplona, España: Aranzadi, 1997.

SeIfert, Achim. El despido basado en la conducta del trabajador en el derecho alemán, en: en: GIL y GIL, José Luis; DeL VAlle, José Manuel (Coords.). El despido disciplinario, Homenaje al Profesor Juan Antonio Sagardoy B. Madrid, España: Ediciones Cinca, 2009.

Sierra Herrero, Alfredo. "Extinción del contrato de trabajo por voluntad del trabajador (jurisprudencia en unificación de la doctrina sobre el artículo 50 ET)", en: Actualidad Laboral N 6, marzo 2007, Madrid, España, La Ley.

Thayer Arteaga, William; Novoa Fuenzalida, Patricio. Manual de Derecho del Trabajo. Tomo III. Santiago, Chile: Editorial Jurídica de Chile, 1998. 